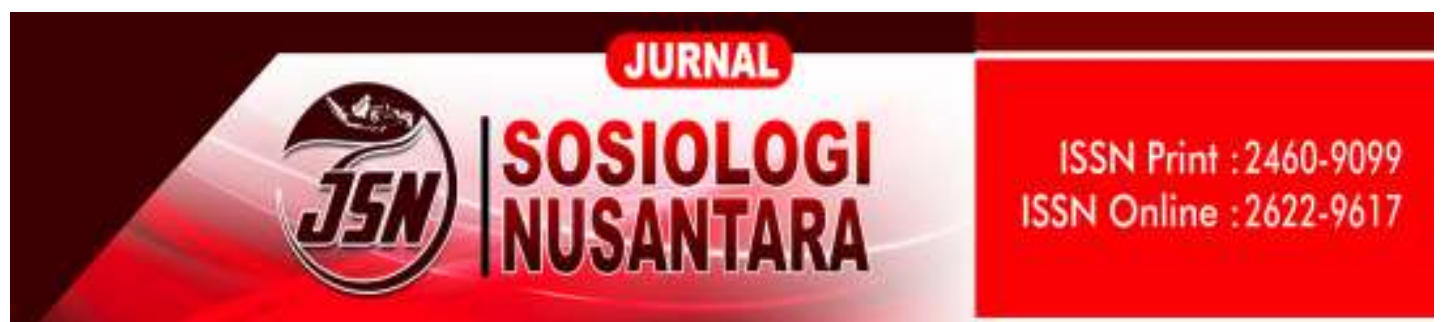

https://ejournal.unib.ac.id/index.php/jsn

DOI ://doi.org/10.33369/jsn.7.1.89-104

\title{
STRATEGI BERTAHAN PEDAGANG BUKU DI TERMINAL SENEN, PROVINSI DKI JAKARTA
}

\section{SURVIVAL STRATEGY OF BOOKSELLER IN SENEN TERMINAL, DKI JAKARTA PROVINCE}

\author{
Omta Purba \\ omta.purba@gmail.com
}

Program Studi Sosiologi Fakultas Ilmu Sosial dan Ilmu Politik Universitas Indonesia

\begin{abstract}
Abstrak
Era digitalisasi menghadirkan efek ganda yakni sebagai simbol kemajuan teknologi dan sekaligus kemunduran dalam beragam ranah yang sebelumnya tidak terkait dengan proses digital tersebut. Industri buku adalah salah satu ranah yang mengalami kemunduran karena kehadiran digitalisasi. Perdagangan buku adalah salah satu sektor yang dapat menggambarkan kemasifan eksistensi digitalisasi yang dimaksud. Hal ini dapat terlihat sejak mulai dari proses pencetakan, penerbitan sampai pada pemasaran buku. Penelitian ini dilakukan di area Terminal Senen, DKI Jakarta, dengan menggunakan pendekatan kualitatif dalam studi kasus. Penelitian ini memiliki tujuan untuk memberikan penjelasan terkait praktik perdagangan buku di Terminal Senen dan strategi bertahan mereka dalam era digitalisasi. Pengumpulan data primer dilakukan dengan memanfaatkan observasi dan wawancara mendalam terhadap sejumlah informan, sementara data sekunder diperoleh lewat sejumlah laporan/ dokumen berita terpercaya dan data statistik. Berdasarkan observasi dan wawancara mendalam tersebut, maka ditemukan dan dihasilkan kesimpulan bahwa para pedagang tetap optimis terhadap kios buku fisik namun dengan pertimbangan bahwa mereka harus mengkolaborasikan metode pemasaran dan perdagangan online dan konvensional. Sebab masih ada pelanggan yang mengaku lebih nyaman dan puas ketika datang untuk memilih dan membawa pulang buku fisik. Selain itu, sejarah dan ingatan masyarakat terhadap perdagangan buku di Terminal Senen yang sudah berlangsung selama puluhan tahun tidak mudah diabaikan begitu saja. Lebih lanjut, eksistensi kelompok Etnis Batak yang mendominasi perdagangan buku di sana menjadi kasus menarik untuk dikaji.
\end{abstract}

Kata Kunci: Perdagangan Buku, Strategi Bertahan, Terminal Senen 


\begin{abstract}
Digitalization presents a dual effect, specifically as a symbol of changing technological advancement and as deterioration in various areas that were not related to the digital process. The printing industry is one of the many aspect areas affected by the digitalization. Bookselling is one of the sectors that can be illustrated by the existence of digitalization. It can be seen from the start of the printing process, publishing to the marketing of books. This study was conducted in the Senen Terminal area, DKI Jakarta province. Using qualitative approach in the case study, this study aims to explain the practice of bookselling at Senen Terminal and how they survive in the digitalization era. Primary data collected by utilizing the collected observation and in-depth interviews with several informants, while secondary data collected through reliable news reports/documents and statistical data. Based on observations and in-depth interviews, the booksellers still optimist with physical bookselling even if it has to consider collaboration between online and convensional marketing and selling methods. Customers claim that they feel comfortable and satisfied when they come to choose physical books and bring them home. Besides, the historical memory of the bookselling at Senen Terminal has been going on for decades and hard to ignore. Furthermore, the existence and domination of the Batak ethnic group in that area, make it an interesting case to study.
\end{abstract}

Keywords: Bookseller, Senen Terminal, Survival Strategy

\title{
PENDAHULUAN
}

Riset Ikatan Penerbit Indonesia (IKAPI) mencatat penerbitan buku konvensional Indonesia mengalami penurunan (IKAPI, 2015), meskipun pada dasarnya jumlah penerbit yang bergabung mengalami pertambahan. Hal tersebut diikuti dengan penurunan pada sejumlah arena pemasaran seperti yang diakui oleh pihak Gramedia yang mengalami penurunan penjualan sebesar 10\%. Dalam hal ini, Gramedia mampu mewakili keadaan penjualan buku Indonesia, sebab sebanyak $61 \%$ dari buku yang diterbitkan akan didistribusikan ke Gramedia dan sisanya yakni sebanyak 39\% akan didistribusikan kepada toko-toko buku kecil atau mandiri lainnya (Handayani, 2016).

Sementara pada sisi penikmat buku, masyarakat mengalami kenaikan minat baca berkat interaksi pembaca yang dilakukan berbasis daring (Wakil Ketua Bidang Humas, Riset, dan Informasi IKAPI Pusat (dalam Ratnasari, 2017). Sebagai contoh, kehadiran e-book yang memudahkan pembaca untuk dapat melakukan kegiatan tersebut tanpa dibatasi ruang dan waktu sekalipun. Belum lagi kemudahan yang dimiliki sejumlah platform internet ketika menawarkan akses terhadap sejumlah 
materi pembelajaran. Lebih lanjut, menjamurnya penjualan buku secara online juga dianggap sebagai alternatif penjualan buku dengan cara yang mudah. Namun demikian, eksistensi online platform sebagai salah satu cara alternatif penjualan buku, belum tentu dapat mengimbangi sumbangan penjualan buku fisik, seperti yang diungkapkan dan dialami oleh toko buku Books \& Beyonds (B\&B) milik Lippo Group (Fauzie, 2018).

Pengakuan tersebut juga dibuktikan oleh picodi.com yang melakukan riset dalam bentuk survei responden yang didasarkan pada data internal platform ecommerce global mereka. Riset tersebut menemukan bahwa sebanyak 47\% responden lebih memilih untuk mendapatkan buku di toko buku konvensional dan sebanyak $73 \%$ responden juga ditemukan lebih memilih format buku biasa yang tersedia di toko buku (Picodi, 2019). Namun demikian terdapat fakta yang tidak dapat diabaikan juga bahwa sejumlah toko buku telah mengalami kebangkrutan hingga harus menutup gerai mereka di beberapa kota seperti Alebene di Bandung, Eureka di Jakarta, Aksara di Jakarta, Toko Buku Djawa di Bandung, dan Gunung Agung di Bandung. Melalui gambaran tersebut di atas, terlihat bahwa selama beberapa tahun terakhir telah terjadi fluktuasi dalam proses perdagangan buku di Indonesia, yang mencakup penerbitan hingga terlebih pada perdagangannya.

Toko buku merupakan salah satu pusat dari kegiatan yang berorientasi pada buku, yang melibatkan sederet aktivitas seperti penerbitan, pengangkutan, pencetakan, penyusunan hingga pada keterkaitannya dengan perdagangan buku yang sesungguhnya (Maceviciute, Wallin, and Nilsson, 2015). Pasar Senen merupakan salah satu pasar tertua yang masih eksis di Jakarta (Ahyat, 1998), dimana terdapat perdagangan buku ikonik dalam jejeran kios-kios yang berpusat di Terminal Senen dan sebagian kecil yang terdapat di lantai V, Gedung Pasar Jaya Pasar Senen (sebelah Terminal Senen).

Perdagangan buku Terminal Senen yang berjumlah kira-kira 56 kios menurut informan PT, didominasi oleh pedagang yang beretnis Batak dan selebihnya dihuni oleh etnis Jawa, Madura dan Padang. Sebagai pedagang buku pindahan dari Lapangan Banteng, para pedagang buku di tempat ini masih terus berupaya eksis bertahan di antara sejumlah penggambaran terkait industri perdagangan buku yang 
disebutkan sebelumnya. Sementara para pembeli yang datang untuk mencari buku di area tersebut berasal dari sejumlah daerah di Indonesia yakni para mahasiswa, pelajar sekolah, dan pengajar yang memiliki orientasi akademis; serta siapapun yang memiliki kegemaran terhadap buku-buku langka yang memang sudah sulit untuk ditemukan. Jenis-jenis buku yang laku untuk diperdagangkan disana itu sangat variatif namun menurut pengakuan para pedagang yakni lebih berfokus pada buku pelajaran/ non fiksi dan disusul dengan buku berbentuk novel langka maupun anyar/ fiksi.

Eksistensi kelompok etnis Batak yang melakukan kegiatan berdagang buku di Terminal Senen, menjadi menarik untuk dikaji setelah mereka berhasil bertahan dan bahkan sampai mampu mendominasi perdagangan buku di Terminal Senen sejak puluhan tahun. Menjadi pedagang buku konvensional yang tidak sekedar kalah bersaing dalam segi pemanfaatan modal, pengadaan komoditi, manajemen dan bahkan kualitas dari retailer besar lain, namun juga ditambah dengan era digitalisasi yang menawarkan lebih banyak kemudahan dan kepraktisan bagi para calon pembeli, telah menjadi tantangan besar bagi para pedagang buku tersebut untuk mempertahankan profesi mereka. Selain itu, ketika berbicara mengenai buku yang menjadi salah komoditi perdagangan dalam terminal Senen, dimana buku merupakan sumber utama dari pengetahuan dan menjadi medium utama dalam pendidikan (Garwe, 2014).

\section{METODE PENELITIAN}

Penelitian ini melibatkan pendekatan kualitatif dalam studi kasus. Dimana pendekatan kualitatif merupakan penelitian yang memanfaatkan language cases, menggunakan bricolage, mengkaji beragam proses sosial dan beragam kasus sesuai dengan konteks sosialnya serta studi interpretasi ataupun makna dalam setting sosiokultural yang bersifat spesifik (Neuman, 2014). Penelitian dengan pendekatan kualitatif dibangun dengan asumsi bahwa bidang kehidupan sosial tertentu secara intrinsik adalah kualitatif. Hal ini sesuai dengan konteks perdagangan buku di kawasan Terminal Senen yang menyajikan proses sosial dimana sebuah ranah perdagangan buku konvensional dapat bertahan di tengah keniscayaan digitalisasi 
dan lebih lanjut, didominasi oleh kelompok etnis Batak yang merupakan kelompok etnis yang melakukan migrasi ke daerah DKI Jakarta.

Sementara teknik pengumpulan data dalam penelitian ini berlangsung dalam penelitian lapangan yang mencakup pada observasi dan wawancara mendalam kepada para pedagang buku kawasan Terminal Senen yang sudah berdagang kurang lebih 7 tahun lebih hingga 30 tahun lebih. Hal ini sesuai dengan pemahaman teknik pengumpulan data Creswell (2007) yang menjabarkan dan membagi teknik pengumpulan data dalam beberapa bentuk yakni pengamatan (observasi), wawancara mendalam baik terstruktur dan tidak terstruktur, dokumen, dan bahan audiovisual.

Data yang digunakan dalam penelitian ini terbagi dalam 2 jenis yakni data primer dan data sekunder. Dimana data primer diperoleh lewat observasi terhadap situasi dan kondisi dalam konteks area Terminal Senen, DKI Jakarta dan wawancara mendalam kepada sembilan informan yakni pedagang buku di kawasan Terminal Senen yang sudah berdagang dalam kurun waktu lebih dari 7 tahun hingga paling lama adalah 35 tahun. Hal tersebut dilakukan agar dapat memberikan deskripsi dan penjelasan yang menyeluruh mengenai momen perubahan dalam proses perdagangan buku yang sudah berlangsung selama puluhan tahun tersebut. Selain itu, keberagaman durasi berdagang menunjukkan dinamika dalam kebertahanan profesi perdagangan buku kawasan Terminal Senen.

Lebih lanjut pengolahan data dilakukan lewat beberapa proses berikut seperti melakukan transkrip hasil wawancara mendalam dan memilah catatan lapangan; pembacaan ulang terhadap transkrip wawancara hingga memilah serangkaian kata, coding dan kategorisasi data yang bersesuaian, hingga melakukan abstraksi data agar dapat dianalisis dengan merujuk pada pertanyaan penelitian.

\section{PEMBAHASAN}

\section{Deskripsi Kawasan Terminal Senen, Provinsi DKI Jakarta}

Terminal Senen merupakan salah satu dari 21 terminal yang dimiliki oleh Provinsi DKI Jakarta. Terminal tipe B yang dibangun pada 13 April 1980 oleh Gubernur Tjokropranolo kala itu, kini merupakan terminal yang melayani 
transportasi dalam lingkup Provinsi DKI Jakarta saja yakni sebanyak 19 trayek. Terminal Senen memiliki luas sekitar 8916,62 m (Pejabat Pengelola Informasi dan Dokumentasi Prov. DKI Jakarta, 2005) dan terletak pada daerah administrasi Kelurahan Senen, Kecamatan Senen, pada Kota Jakarta Pusat.

Keberadaan Terminal Senen yang melayani transportasi selama puluhan tahun hingga sekarang tidak dapat dilepaskan dari terminal Banteng yang berlokasi tidak terlalu jauh dari kawasan Senen, dimana dulu pernah menjadi terminal namun sekarang beralih fungsi menjadi Taman Lapangan Banteng. Pemindahan terminal dari kawasan Banteng ke kawasan Senen juga telah memicu pemindahan dari para pedagang buku, koran, dan majalah yang turut berpindah. Kemudian pada masa itu, pemerintah daerah berinisiatif untuk membangun blok VI di Pasar Inpres sebagai jawaban atas kesemrawutan yang ditimbulkan oleh para pedagang kali lima yang bertahan di tempat umum seperti Jatinegara, Blok M, dan kawasan Banteng.

Melalui banyak pasang surut dan penyampaian pendapat kepada Unit Pelaksa Teknis Dinas Perhubungan sebagai otoritas pembina para pedagang di kawasan Senen, maka hingga saat ini deretan kios yang berada di kawasan tersebut menjual beragam komoditi seperti sejumlah jenis buku dan sejumlah jenis makananan (seperti buah dan makanan khas etnis Batak). Kios-kios yang berderet pada kawasan terminal tersebut merupakan hasil bangunan dari para pemilik yang harus mengurus Surat Izin Usaha Perdagangan kepada Unit Pelaksana Teknis Dinas Perhubungan Terminal Bus Senen.

Lebih lanjut, apabila menilik pada lokasi dan penempatan dari kios dengan jenis komoditi yang diperdagangkan itu dapat terlihat deretan kios yang tidak mengelompok antar sesama komoditi yang sama. Ketika kita memasuki area pinggir terminal sebelah kiri terminal akan terlihat deretan dominasi kios yang berdagang komoditi makanan dan diselingi oleh sebagian kecil pedagang buku serta lapo yang dipenuhi oleh pengunjung kelompok etnis Batak juga. Sementara pada bagian tengah akan ditemui bangunan pengelola terminal bus Senen sebagai pelaksana otoritas terminal beserta fasilitas toilet, jalur sepeda yang membelah dari area masuk hingga area keluar, sejumlah halte, dan deretan bus transjakarta dan angkutan jak lingko yang turut mengantri dalam menanti pemberangkatan masing-masing. Pada 
bagian pinggir sebelah kanan dari area masuk akan kita temui juga sebuah pos polisi, yang disusul dengan deretan kios buku yang mendominasi hingga ke ujung area keluar terminal Senen. Pada bagian kanan tersebut juga disisipi oleh para pedagang makanan (gorengan, buah, mie sop) dan asongan serta toilet.

Keberadaan kelompok etnis Batak yang mendominasi terminal tersebut juga dapat tersajikan dalam pemandangan dan pendengaran para pengunjung. Sebab kelompok tersebut menghuni kios dan berdagang beragam komoditi seperti makanan, buah dan yang paling mencolok adalah buku. Selain itu, kelompok etnis Batak yang sebelumnya menjadi supir metromini, saat ini beralih menjadi driver berbasis aplikasi online. Kemudian kendaraan bemo sebagai transportasi yang digemari oleh masyarakat Jakarta juga turut menghuni kawasan terminal tersebut. Jejak kelompok etnis Batak juga teramati dalam lapak parkir yang juga dikuasai oleh kelompok tersebut.

\section{Praktik Perdagangan Buku di Terminal Senen}

\subsection{Aktor dan Peran dalam Perdagangan Buku di Terminal Senen}

Dalam sebuah proses perdagangan buku, terdapat beberapa aktor yang berperan yakni para pedagang, pemasok, pengantar, calo, pembeli, pemilik kios, penyewa kios, dan pihak Dinas Perhubungan Terminal Senen. Para aktor ini akan menjalankan fungsi dan peran yang membentang mulai dari pengadaan buku, penjualan buku dan atau ketika dilakukan pengantaran buku dari dan atau kepada pembeli/pelanggan.

a. Pedagang buku

Pedagang buku di kawasan Terminal Senen adalah pedagang yang menempati kios di bagian pinggir dan tersebar pada terminal tersebut. Tidak semua pedagang buku memiliki kios sendiri. Mereka, para pedagang yang tidak memiliki kios, harus menyewa kepada pemilik sewa.

b. Pemasok buku

Para pedagang buku di kawasan Terminal Senen mendapatkan pasokan buku dari beberapa pihak yakni Toko Grosir Maya Indah; pelapak buku kiloan Jatinegara; penerbit; lapak online seperti facebook, lazada, tokopedia, bukalapak; dan individu yang membawa langsung kepada pedagang buku disana. 


\section{c. Pengantar buku}

Jasa pengantaran buku biasanya dimanfaatkan oleh para pedagang buku ketika melakukan penjualan buku dalam jumlah besar untuk mengantarkan menuju pembeli ataupun kepada sesama penjual yang juga turut membeli untuk dijual kembali.

d. Calo buku

Kegiatan percaloan adalah hal yang normal terjadi dalam proses perdagangan buku di Terminal Senen. Jasa calo sering ditujukan untuk membantu baik calon pembeli dan penjual untuk menemukan buku yang dicari, kemudian dari sanalah mereka mendapat komisi. Kegiatan percaloan dapat bermakna dua hal, dimana pada satu sisi buku yang dicari dapat dengan mudah ditemukan, namun pada sisi lain dapat menciptakan harga buku yang lebih tinggi dan terkadang memperpanjang proses transaksi penjualan buku.

e. Pembeli buku

Para pembeli buku adalah mereka yang membeli buku baik secara langsung atau pun tidak langsung (online). Para pembeli buku biasanya datang ke terminal Senen dari banyak kalangan seperti murid sekolah dan orangtua, mahasiswa dan orangtua, dosen, pekerja pemerintah atau swasta, masyarakat biasa yang memiliki kecintaan pada buku.

f. Pemilik kios buku

Para pemilik buku adalah individu yang mendaftarkan namanya kepada pihak otoritas Terminal Senen sebagai penyewa lahan, dimana mereka harus mengurus SIUP pada awal proses tersebut. Pemilik kios tidak selalu memanfaatkan kios yang sudah disewa tersebut untuk dirinya sendiri, namun seringkali disewakan kembali kepada pihak lain.

g. Penyewa kios buku

Sementara penyewa kios adalah pedagang yang memanfaatkan kios untuk aktivitas perdagangan buku. Biasanya mereka akan menyewa kios dengan sistem sewa perbulan. Para penyewa kios ini biasanya merupakan para anak buah dari pemilik toko yang ingin berupaya berdagang secara mandiri dengan menyewa kios sendiri. 
h. Pengelola Terminal Senen

UPT Dinas Perhubungan Prov. DKI Jakarta Terminal Bus Senen adalah pengelola yang membawahi keseluruhan usaha dan bangunan kios yang terdapat di Terminal Senen. Setiap SIUP yang ingin diurus oleh para pihak yang ingin membuka usaha berdagang di lingkup Terminal Senen akan ditujukan kepada pihak pengelola terminal Senen. Maka dari itu, setiap kios yang sudah memiliki Izin Usaha harus membayar retribusi kepada no.rek UPT Dinas Perhubungan Terminal Bus Senen. Pengelola Terminal Senen memberlakukan perjanjian bahwa pihak mereka berhak untuk mencabut Izin Usaha, memindahkan ataupun menggusur kios kelolaan mereka tanpa pengajuan tuntutan dari para pemilik atau penyewa kios tersebut.

\subsection{Dominasi Kelompok Etnis Batak dalam Perdagangan Buku Terminal Senen}

Keberadaan kelompok etnis Batak dalam kawasan Senen secara umum dapat digambarkan sebagai berikut. Kelompok etnis Batak terlihat mengambil bagian dalam kepemilikan sejumlah kios dengan izin usaha milik pribadi disana. Selain itu tentu saja jaringan modal sosial yang dimiliki telah merambah pada penyewaan kios untuk perdagangan beragam komoditi disana. Kelompok ini juga banyak mengambil pekerjaan dalam bidang transportasi, percaloan, dan parkir pada kawasan tersebut. Perdagangan buku merupakan salah satu ranah paling nyata dimana kelompok ini mendominasi. Hal tersebut dapat teramati dalam keseluruhan proses perdagangan buku mulai dari kepemilikan kios, pengadaan buku, pedagang grosir dan eceran, hingga percaloan. Kelompok etnis yang bermigrasi ke tiga kota besar seperti Medan, Bandung dan Jakarta ini memiliki variasi adaptasi tersendiri sesuai dengan situasi urban tersebut (Bruner, 1972).

\subsection{Dilema Buku Asli dan Buku Bajakan}

Fenomena pembajakan telah mengancam keuntungan industri yang mungkin diperoleh terkait hak cipta seperti yang dapat ditemui dalam ranah musik, perangkat lunak video dan buku (Dionísio et al., 2013). Pembajakan tidak hanya mencuri upaya intelektual dan kreatif dari penulis lain, namun juga mengurangi standar dan kualitas dari karya asli serta pendapatan yang mungkin saja diperoleh lewat karya 
asli tersebut juga ikut terabaikan (Igesha, 2019). Namun tampaknya para pedagang buku di terminal tersebut tetap bergeming. Perdagangan buku di terminal Senen tetap menjual beragam buku baik asli dan bajakan. Perdagangan buku bajakan seolah sudah menjadi hal lumrah dan diabaikan oleh sejumlah pihak. Para pedagang tidak keberatan menjual buku bajakan selama pembeli berkenan membeli. Penyidakan yang dilakukan oleh IKAPI tidak mengurungkan niat pedagang untuk tetap melakukan bisnis perdagangan buku bajakan ini.

Keberadaan organisasi Paguyuban Pedagang Buku Senen memainkan peran yang besar ketika tindak penyidakan dilaksanakan. Penyidakan berlangsung sewaktu-waktu tanpa pemberitahuan, menuntut kehadiran informasi dari pengurus paguyuban tersebut yang akan diteruskan kepada pedagang buku. Informan PT dalam wawancaranya menyampaikan bahwa penyidakan tersebut berlangsung dengan melibatkan aparat penegak hukum juga, meskipun menurut informan TU pedagang yang terbukti memperjualbelikan buku bajakan hanya diberikan surat peringatan dan surat perjanjian yang menuntut komitmen mereka agar tidak memperjualbelikan buku bajakan lagi.

Pedagang tampaknya tidak terlalu terganggu dengan adanya penyidakan ini karena menurut mereka selama pembajak masih terus menawarkan produk bajakan dan diikuti oleh permintaan atau lebih tepatnya keabaian para calon pembeli atas keberadaan buku bajakan tersebut, maka mereka masih akan tetap melakukan tindakan perdagangan buku bajakan tersebut. Harga buku murah telah menjadi daya tarik dari buku bajakan yang tidak bisa dikesampingkan oleh para calon pembeli yang memang memiliki tujuan mendapatkan buku murah di kawasan Senen tersebut. Selain itu, calon pembeli mengaku akan lebih mengutamakan konten buku yang masih dapat dibaca dengan baik daripada harus menolak maraknya kasus perdagangan buku bajakan di sana.

\section{Strategi Bertahan Pedagang Buku di Terminal Senen}

\subsection{Kolaborasi Perdagangan Buku Online dan Konvensional}

Sejumlah informan menyatakan bahwa semenjak era digital (khususnya 3-5 tahun belakangan), cara pemasaran dan perdagangan buku online dan konvensional 
telah menjadi pilihan realistis. Bahwa meskipun kios buku fisik yang berada di terminal Senen tetap buka, namun waktu buka mereka tidak sebanyak sebelum mereka menggunakan platform pemasaran online. Sehingga secara tidak langsung perubahan ini diakibatkan oleh geliat pemasaran dan perdagangan buku yang terjadi secara online.

Meskipun memang tidak dapat dipungkiri bahwa masih terdapat faktor kepuasan apabila datang dan memilih langsung buku yang ingin dibeli. Calon pembeli mahasiswa biasanya datang untuk membeli buku sebagai referensi untuk tugas akhir dan atau buku yang dibutuhkan untuk mata kuliah per semester. Apabila buku yang dicari tidak ditemukan, maka biasanya mereka akan mencari kesesuaian dengan cara membandingkan daftar isi buku yang mereka cari dengan daftar isi dari buku alternatif yang ditawarkan oleh pedagang buku di kawasan Terminal Senen. Sementara itu mahasiswa yang sudah memiliki pilihan buku yang pasti lebih memilih untuk mencari buku lewat mesin pencarian penyedia buku melalui sejumlah platform.

Demi memenuhi permintaan konsumen dan upaya bertahan atas perdagangan buku yang digeluti, maka para pedagang buku juga secara beramai-ramai ikut memasarkan komoditi buku mereka lewat beragam platform seperti shoppee, bukalapak, tokopedia dan media sosial facebook. Dimana menurut para pedagang buku terdapat perbedaan mendasar antara pemasaran melalui platform belanja dengan pemasaran melalui media sosial seperti facebook. Media sosial facebook hanya dapat ditujukan sejauh kepada lingkaran pertemanan yang terjalin dalam platform tersebut. Selain itu, informan mengaku terdapat narasi 'dijual cepat' yang turut mempermudah proses jual beli dilakukan. Sedangkan proses pemasaran dan jual beli yang dilakukan melalui platform online shop diyakini oleh beberapa pedagang buku Senen mampu menjangkau konsumen secara lebih luas dan jauh serta tidak hanya berbasis pertemanan dari para pemilik akun media sosial tersebut.

Ketidakterpisahan antara kios buku fisik dan kios buku online melalui beragam platform telah mewujud dalam sejumlah upaya merangkul kemajuan digitalisasi masa kini. Namun demikian, kemajuan perdagangan buku belum terlalu tangguh untuk sampai menghilangkan keberadaan dan perdagangan buku fisik. 
Sebab para pedagang buku di Terminal Senen mengaku pembeli sendiri yang menyatakan bahwa mereka tidak selalu nyaman dengan metode membaca buku dalam wujud ebook. Meskipun ebook menawarkan sejumlah kemudahan untuk tidak harus mencetak buku secara fisik dan mengeluarkan sejumlah dana untuk itu, namun konsumen buku memilih tetap ingin membawa pulang buku secara fisik. Selain itu, buku fisik yang sudah dibeli dapat menghadirkan sense of belonging tersendiri terhadap buku tersebut bagi pemilik buku. Dengan demikian muncul upaya untuk menjaga dan merawat buku tersebut.

Selain itu, keberadaan kios buku fisik penting ditemui dalam sebuah kota sebab akan menghadirkan sebuah image kota yang berbudaya dan bermanfaat bagi generasi muda (Di, 2017). Hal ini dibuktikan dengan keberadaan sejumlah kios buku yang terdapat pada sejumlah titik di DKI Jakarta dan menjadi tujuan dan rujukan dalam perburuan buku bagi banyak daerah di Indonesia. Perdagangan buku di kawasan Senen juga telah menjadi rujukan pembelian buku kalangan muda terlebih dalam perburuan buku langka dan unik selama puluhan tahun terlepas dari semua keadaan mereka sekarang.

\subsection{Sejarah Terminal Senen: Buku dan Senen adalah Dua Hal yang Tidak Bisa Dipisahkan}

Keberadaan pedagang buku Senen sejak tahun 1980an telah melekat dalam ingatan masyarakat (khususnya wilayah Jakarta dan sekitarnya). Hal ini terbukti bahwa pelanggan buku Senen telah tersebar dari banyak daerah di Indonesia. Meskipun secara khusus masyarakat Jakarta dan sekitarnya adalah para pelanggan dekat, namun terbukti masyarakat dari daerah Indonesia lain juga turut melanggan kepada pedagang buku kawasan Senen. Hal ini dibuktikan dengan permintaan buku dari sejumlah daerah baik untuk perkuliahan atau untuk melengkapi perpustakaan di beberapa daerah menurut informan yang pernah melayani permintaan buku dalam jumlah besar tersebut.

DKI Jakarta memiliki beberapa tempat perdagangan buku yang masih eksis seperti Kwitang, Blok M, Pasar Kenari Lama, dll, namun Terminal Senen bukanlah tempat perdagangan buku yang bisa diabaikan begitu saja. Sejumlah pedagang yang 
membuka usaha perdagangan buku di sejumlah tempat Jabodetabek masih memilih menambah pasokan komiditi buku mereka dari grosir atau pedagang yang berada di kawasan Senen. Kelengkapan persediaan buku adalah jawaban dari hal tersebut. Pengalaman proses perdagangan buku selama puluhan tahun tidak bisa diabaikan ketika pengetahuan terkait buku dibutuhkan. Para pedagang buku kawasan Senen yang sudah melakukan praktik perdagangan buku bahkan sejak kepindahan mereka dari lapangan Banteng telah membentuk pengetahuan mereka terkait buku dan pasar buku itu sendiri.

Belum lagi permintaan akan buku langka yang memang sudah memiliki jaringan tersendiri bagi para pedagang buku lama kawasan Senen. Pengetahuan para pedagang buku terkait konten buku juga patut untuk disoroti sebab mereka bisa mengarahkan calon pembeli terhadap buku-buku terkait yang seharusnya menjadi bagian tak terpisahkan ketika membeli buku untuk suatu tema tertentu. Perdagangan buku tersebut juga telah membawa mereka dekat dengan sejumlah akademisi dan pejabat yang kerap melanggan buku yang mereka jual.

Selain itu, praktik penjualan buku bajakan adalah fakta yang ditemui di lapangan. Ketika oknum tertentu menawarkan kumpulan buku bajakan kepada para pedagang, maka hal tersebut dapat diterima oleh pedagang selama permintaan akan buku murah masih ada. Pembeli sangat dapat mengabaikan faktor keaslian buku selama konten yang ditawarkan sama persis dengan buku yang dicari. Sederet hal tersebutlah yang dimiliki oleh perdagangan buku kawasan Senen yang mampu mengangkat nama dan sejarah kawasan Senen sebagai salah satu surga buku di ibukota.

\subsection{Kegigihan Pedagang Buku Kelompok Etnis Batak}

Kelekatan image kawasan Terminal Senen dengan kelompok etnis Batak adalah kolaborasi yang paling banyak diingat oleh para pengunjung. Pengunjung hampir selalu mengasosiasikan kelompok etnis Batak dengan kawasan terminal ini. Dimana kelompok etnis yang biasanya melakukan migrasi seperti pada kelompok etnis di Terminal Senen tersebut, memiliki karakter berbicara dengan volume keras dan tegas serta memilih profesi sebagai pedagang buku bukanlah profesi yang lazim bagi kelompok etnis tersebut (Sinaga, 1993). Meskipun terdapat juga etnis lain yang 
ikut melakukan praktik perdagangan sejumlah komoditi di terminal tersebut, namun kelompok etnis Batak sudah eksis sejak lama dan mendominasi kawasan tersebut.

Kelompok etnis Batak dikenal dengan image gaya berbicara kasar, spontan dan nada bicara yang tinggi. Apabila kita memasuki area Terminal Senen, hal tersebut masih sangat dapat ditemui. Hal ini juga diamini oleh informan yang menyatakan bahwa gaya bicara demikian dapat mempengaruhi calon pembeli saat hendak membeli ataupun melakukan transaksi jual beli. Beberapa pedagang yang paham memang sudah mengubah gaya bicara dan sikap mereka, meskipun sebagian lagi masih tidak bisa melepaskan kebiasaan berbicara tersebut.

Namun di luar itu semua, kegigihan para pedagang untuk tetap menawarkan komoditi buku mereka yang dapat terlihat dalam memanggil calon pelanggan dari posisi jauh, menawarkan mencari buku apabila tidak ada persediaan buku yang dimaksud di kiosnya, memberikan alternatif buku lain berdasarkan pemahaman atas konten buku yang dicari calon pembeli dan yang terakhir dengan etos kerja yang tinggi untuk memajukan usahanya lewat banyak cara yang ditempuh seperti memperdalam pemahaman atas buku, upaya memoles buku langka agar terlihat lebih bernilai demi meningkatkan nilai jual buku tersebut. Dalam lingkup yang lebih besar, pedagang buku kawasan Senen punya misi personal tentunya untuk mensejahterakan keluarga mereka secara ekonomi dan terutama melalui jalur pendidikan tertinggi untuk anak-anak mereka. Para pedagang yang menjadi informan dari penelitian ini dengan bangga menyampaikan kisahnya kepada peneliti bahwa anak-anak mereka mampu maju bahkan hingga strata 2 melalui perdagangan buku yang digeluti tersebut.

\section{KESIMPULAN}

Bukan hal yang mudah untuk bertahan di tengah era digitalisasi, dimana industri buku mengalami akibat mulai dari proses penerbitan hingga pemasaran. Perdagangan buku di kios buku mandiri seperti kawasan Terminal Senen adalah salah satu tempat dimana dapat terlihat deskripsi dan uraian proses dari hulu ke hilir tersebut. Dalam uraian di atas telah terlihat bagaimana para pedagang buku dalam 
kawasan tersebut berupaya bertahan dalam riuh digitalisasi yang mengancam eksistensi kios buku secara fisik.

Berdasarkan analisis terhadap data di lapangan maka ditemukan sejumlah strategi yang dilakukan pedagang dalam mempertahankan perdagangan buku yang menjadi sumber kehidupan mereka yakni: a. Kolaborasi pemasaran dan perdagangan buku secara online dan konvensional; b. Pemanfaatan sejarah dan ingatan yang sudah lekat pada masyarakat bahwa kawasan Senen dan buku adalah dua hal yang tak terpisahkan, masyarakat memiliki pemahaman bahwa kalau mau mencari buku murah dan langka maka kawasan Terminal Senen adalah jawaban; c. Kegigihan yang dimiliki oleh pedagang buku etnis Batak yang banyak mendominasi perdagangan buku di kawasan tersebut.

\section{DAFTAR PUSTAKA}

Ahyat, Ita Syamtasiyah. 1998. Pasar Tua Di DKI Jakarta: (Pasar Baru, Pasar Glodok, Pasar Ikan, Pasar Senen, Pasar Tanah Abang). Depok.

Bruner, Edward M. 1972. Batak Ethnic Associations in Three Indonesian Cities. The University of Chicago Press Journals 28(3).

Creswell, J. W. 2007. Qualitative Inquiry and Research Design: Choosing Among Five Approaches. In L. C. Shaw (Ed.), Health Promotion Practice (Second, Vol. 16, Issue 4). Sage Publication. https://doi.org/10.1177/1524839915580941

Di, Qi. 2017. An Examination of the Effects of Service Quality, Student Satisfaction and University Reputation on Student Loyalty." Pp. 1-217 in International Conference in Innovative Business and Entrepreneurship, edited by R. Paengkaesorn. Lak Hok: Rangsit University.

Dionísio, Pedro, Carmo Leal, Hélia Pereira, and Maria Fátima Salgueiro. 2013. Piracy Among Undergraduate and Graduate Students: Influences on Unauthorized Book Copies. Journal of Marketing Education 35(2).

Fauzie, Yuli Yanna. 2018. Penjualan Buku Tergerus, Toko Buku Milik Lippo Genjot e-Book.

Retrieved (https://www.cnnindonesia.com/ekonomi/20180417174106-92291485/penjualan-buku-tergerus-toko-buku-milik-lippo-genjot-e-book).

Garwe, Evelyn Chiyevo. 2014. Reducing Book Piracy: The Role of the Higher Education Sector. International Research in Education 2(2).

Handayani, Maulida Sri. 2016. Me (mendeley)lawan Goliat Perdagangan Buku. 
Retrieved (https://tirto.id/melawan-goliat-perdagangan-buku-835).

Igesha, Peter M. 2019. Assessing the Role of Demand and Supply Apects in Book Piracy: Case of Nairobi City County, Kenya. Kenyatta University.

IKAPI. 2015. Buku Indonesia Dalam Angka. Jakarta.

Maceviciute, Elena, Birgitta Wallin, and Kersti Nilsson. 2015. Book Selling and EBooks in Sweden. Libellarium 8(1):15.

Neuman, W. Lawrence. 2014. Social Research Methods: Qualitative and Quantitative Approaches. Seventh. edited by Y. K. Djamba. Essex: Pearson Education Limited.

Picodi. 2019. "Pembelian Buku Di Indonesia (Dan Di Seluruh Dunia)." Retrieved (https://www.picodi.com/id/mencari-penawaran/pembelian-buku-di-indonesiadan-di-seluruh-dunia).

PPID Prov.DKI Jakarta. 2005. Data Terminal Prov. DKI Jakarta. Retrieved (www.ppid.jakarta.go.id).

Ratnasari, Yuliana. 2017. IKAPI: Minat Baca Meningkat, Penjualan Buku Menurun. Retrieved (https://tirto.id/ikapi-minat-baca-meningkat-penjualan-bukumenurun-cnpA).

Sinaga, Dannerius. 1993. Aktivitas Ekonomi Dan Sistem Kekerabatan Orang Batak Toba Di Jakarta: Studi Kasus Pedagang Dan Calo Buku Senen. Universitas Indonesia. 